\title{
Pulmonary artery banding for idiopathic dilative cardiomyopathy: A novel therapeutic strategy using an old surgical procedure
}

Dietmar Schranz, MD, Alex Veldman, MD, Ulrike Bartram, MD, Ina Michel-Behnke, MD, Jürgen Bauer, MD, and Hakan Akintürk, MD, Giessen, Germany

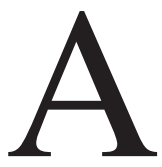

2-month-old infant with progressive idiopathic dilative cardiomyopathy (iDCM) who was listed for heart transplantation recovered dramatically from end-stage heart failure after pulmonary artery banding (PAB). To our knowledge, the use of PAB to treat left-sided iDCM has not been described in the literature.

From the Pediatric Heart Center, Justus-Liebig University, Giessen, Germany. Received for publication April 6, 2007; accepted for publication April 16, 2007.

Reprint requests: Dietmar Schranz, MD, Pediatric Heart Center, JustusLiebig University Feulgenstrasse 12, 35385 Giessen, Germany (E-mail: Dietmar.Schranz@paediat.med.uni-giessen.de).

J Thorac Cardiovasc Surg 2007;134:796-7

$0022-5223 / \$ 32.00$

Copyright $\odot 2007$ by The American Association for Thoracic Surgery doi:10.1016/j.jtcvs.2007.04.044

\section{Clinical Summary}

The patient presented during fetal life with massive dilation and reduced systolic function of the left ventricle (LV). At 35 weeks of gestation, delivery became necessary because of progressive deterioration of heart function. A postnatal echocardiogram showed an extremely dilated LV (Figure 1, A) with an ejection fraction of 13\%. The male newborn (weight $2370 \mathrm{~g}$ ) was treated with controlled ventilation, inotropics, and prostaglandin $\mathrm{E}_{1}$ for contribution of the right ventricle (RV) to cardiac output through the arterial duct. When secondary causes of dilative cardiomyopathy were ruled out, the patient was listed for heart transplantation; 2 months after this, we decided to perform a central PAB, because $\mathrm{PAB}$ is an established approach for patients with a morphologic $\mathrm{RV}$ in systemic position to retrain the $\mathrm{LV}$ and to improve $\mathrm{RV}$ failure and ameliorate tricuspid insufficiency. ${ }^{1,2}$ The local ethics
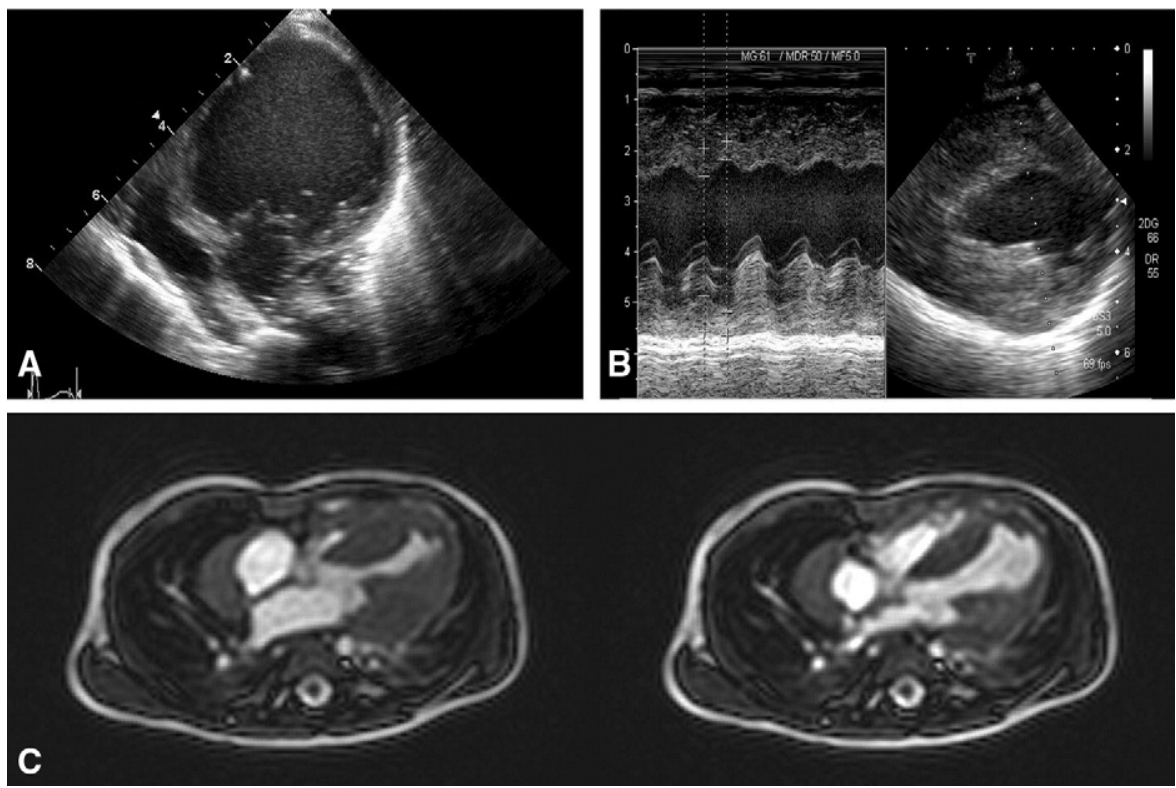

Figure 1. Treatment of idiopathic dilated cardiomyopathy with PAB. Echocardiography demonstrates the extremely dilated LV before PAB was surgically performed. The measured LV end-diastolic diameter was $41 \mathrm{~mm}$. Both the LV posterior wall dimension and the diastolic dimension of the interventricular septum were $3 \mathbf{~ m m}$ (apical 4-chamber view) (A). Six weeks after banding, echocardiographic assessment revealed a decrease of the LV end-diastolic diameter to $30 \mathrm{~mm}$ with a significant improvement of systolic function (m-mode, 2-dimensional recording) (B). At the age of 6 months, cardiac magnetic resonance imaging showed a concentric hypertrophy of the LV with a normal systolic function, instead of the expected RV hypertrophy with a remaining LV dilation. Magnetic resonance imaging measurements revealed an LV end-diastolic diameter of

$24 \mathrm{~mm}$, LV posterior wall dimension of $9 \mathrm{~mm}$, and interventricular septal defect of $12 \mathrm{~mm}$. The calculated ejection fraction was $62 \%$ (systolic and diastolic phase in magnetic resonance imaging 4-chamber view) (C). 
committee approved the procedure. Informed consent was obtained from the parents. The intraoperative pressure gradient across the PAB was adjusted to $45 \mathrm{~mm} \mathrm{Hg}$ (half systemic), which increased to $65 \mathrm{~mm} \mathrm{Hg}$ when the infant was discharged 4 weeks later. Rehabilitation of the LV shape and improvement of function, accompanied by a diminution of the mitral regurgitation, were observed by repositioning of the ventricular septum as an immediate LV-RV cross-talk. At the 6-week and 6-month follow-ups, dramatic changes of the LV morphology were documented by echocardiography (Figure 1,B) and magnetic resonance imaging (Figure 1,C), respectively. At the age of 1 year, the patient underwent balloon dilatation of the PAB to decrease RV pressure from the systemic level to a systolic RV pressure of $45 \mathrm{~mm} \mathrm{Hg}$. Magnetic resonance imaging 3 weeks after the intervention showed a still hypertrophied LV with an ejection fraction of $66 \%$. Brain natriuretic peptide levels decreased from a 2-peak maximum of $6910 \mathrm{pg} / \mathrm{mL}$ (postnatally) and $2923 \mathrm{pg} / \mathrm{mL}$ (before PAB) to normal values of $87 \mathrm{pg} / \mathrm{mL}$ after the intervention, corresponding with the patient's excellent clinical condition.

\section{Discussion}

This report describes the first-time application of PAB for the treatment of iDCM in an infant with LV failure who was listed for heart transplantation. The rationale for such surgical treatment derives from convincing results with $\mathrm{PAB}$ in patients with a subaortic RV. ${ }^{1,2}$ We recognize the limitations of a single case report, but we are convinced that $\mathrm{PAB}$ is a promising adjunctive novel therapy for left-sided iDCM, particularly at this young age. We found an immediate cross-talk between the pressure-loaded $\mathrm{RV}$ and the dilated LV in terms of resynchronization of the LV by reshifting the interventricular septum. In addition, PAB had a direct impact on the mitral regurgitation. In consideration of the possible long-term perspectives of this approach, the first goal was to retrain the RV to work in synchrony with the failing LV by performing a Damus-Kaye-Stansel operation combined with a Glenn-Shunt in the further follow-up. This idea was created in the context of our experience with the hybrid strategy in newborns with hypoplastic left-sided heart complex. ${ }^{3}$ However, the mechanism of the concentric remodeling with improved function of the $\mathrm{LV}$ in response to the chronic pressure load of the RV was surprising and led to a change in our decision making only for unloading the RV by balloon dilation of the pulmonary banding. However, the mechanism of LV remodeling needs to be elucidated. Synergy among postnatal physiologic cardiac growth, cardiomyopathic background, ${ }^{4}$ and changes of biventricular gene expression in the setting of RV pressure overload ${ }^{5}$ may play a role.

\section{References}

1. Winlaw DS, McGuirk SP, Balmer C, Langley SM, Griselli M, Stümper O, et al. Intention-to-Treat analysis of pulmonary artery banding in conditions with a morphological right ventricle in the systemic circulation with a view to anatomic biventricular repair. Circulation. 2005;111:405-11.

2. Poirier N, Mee R. Left ventricular reconditioning and anatomical correction for systemic right ventricular dysfunction. Semin Thorac Cardiovasc Surg Pediatr Card Surg Annu. 2000;3:198-215.

3. Akintuerk H, Michel-Behnke I, Valeske K, Mueller M, Thul J, Bauer J, et al. Hybrid transcatheter-surgical palliation; basis for univentricular or biventricular repair, the Giessen experience. Pediatr Cardiol. 2007;28: 79-87. Epub 2007 Feb 15

4. Syed F, Odley A, Hahn HS, Brunskill EW, Lynch RA, Marreez Y, et al. Physiological growth synergizes with pathological genes in experimental cardiomyopathy. Circ Res. 2004;95:1200-1.

5. Roncon-Albuquerque $\mathrm{R}$, Vasconcelos $\mathrm{M}$, Lourenco AP, BrandoNogueira A, Teles A, Henriques-Coelho T, et al. Acute changes of biventricular gene expression in volume and right ventricular pressure overload. Life Sci. 2006;78:2633-42. 